\title{
Analysis of Planar Inverted-F Antenna (PIFA) U-Shaped at 2.4-3.7 Ghz for 5G Communication
}

\author{
Gerry Glenaldy Warae \\ Gunadarma University \\ Jakarta, Indonesia
}

\author{
Debyo Saptono \\ Gunadarma University \\ Jakarta, Indonesia
}

\begin{abstract}
The PIFA u-shaped design process is carried out by using math formulation and experimental methods with several reference of processors journal helps. For simulate it, it uses some software. Magus Antenna is one of them for designing purpose and for simulating and optimizing the Antenna is using the CST Studio Suite 2020 software. The PIFA optimization process is carried out by changing the antenna dimension elements, to get the IEEE defined standards, which is $\operatorname{VSWR} \leq 1$, reference impedance $50 \Omega$, and s-parameter below $-20 \mathrm{~dB}$.

The results obtained in the form of slot 1 antenna that works at a frequency of $2.4 \mathrm{GHz}$ and slot 2 at a frequency of 3.7 GHz. The results obtained are the value of slot 1 and slot 2 . VSWR has a value of 1.10090581 and 1.09702511. The return loss is -26.369808 and -26.69439 . The gain is worth 3.49 and 2.82. The antenna has a line impedance of $50.150508 \Omega$ which has a tolerance of $0.150508 \Omega$.
\end{abstract}

\section{Keywords}

5G Communications, Planar Inverted-F Antenna (PIFA), PIFA U-Shaped, Antenna parameters, VSWR, Line Impedance, Return Loss, Gain, Radiation Pattern.

\section{INTRODUCTION}

The PIFA antenna is an inverted-F planar antenna which has several advantages, namely it has two slots, each of which can be used for two different frequency signals. [1] The frequency that can be delivered by PIFA is in the mid band range. The government is still considering the frequencies to be used in $5 \mathrm{G}$ communication in Indonesia. On several news portals, it was reported that the frequencies to be used by $5 \mathrm{G}$ communications are $2.3 \mathrm{GHz}, 700 \mathrm{MHz}, 2.6 \mathrm{GH}$ and $3.5 \mathrm{GHz}$. Therefore, the PIFA antenna is considered suitable for use in 5G communication because it can provide two frequency slots. The frequency taken is the middle frequency that will work in the mid band, namely the $2.4 \mathrm{GHz}$ and $3.7 \mathrm{GHz}$ frequencies. PIFA has several

types of slots, namely PIFA V-shaped, PIFA L-shaped, and PIFA U-shaped. In several journals that discuss the three types of PIFA, they describe their advantages and disadvantages.[2] In reference journals, the majority of the results show that the U-shaped PIFA is superior to other PIFA types. Therefore, researcher design and analyze the U-shaped PIFA for $5 \mathrm{G}$ communication.[3]

$5 \mathrm{G}$ communication is a technology that has a much higher data rate than $4 \mathrm{G}$. [4] The data speed offered by this technology is estimated to reach $\mathrm{Gb} / \mathrm{s}$ which previously only reached tens of $\mathrm{Mb} / \mathrm{s}$. Every communication technology definitely requires an antenna as a transmitter and receiver. [5]
Antenna is a tool for sending and receiving electromagnetic waves, depending on the usage and frequency usage. So, in designing the PIFA on $5 \mathrm{G}$, it is necessary to know the $5 \mathrm{G}$ frequencies that will be applied in Indonesia first. The parameters of the antenna are VSWR, bandwidth, Return Loss, Line Impedance, and radiation pattern. These parameters are determined with the aim that the antenna can meet the criteria and can work on a 5G network. [6]

\section{PLANAR INVERTED F ANTENNA}

PIFA designs tend to be low profile, light weight and efficient space filling structures, and as such, are particularly attractive for handset and terminal applications. Conventional PIFA designs have constrained bandwidth; however, it is possible to realize novel structures which are electronically tunable over most of the wireless communication bands. Tunable multi-functional handset modules employ the same basic design aims to provide favorable trade-offs in terms of volume, weight and performance. Many interesting PIFA, and more general tuned printed antennas, have been proposed. Various switching technologies, such as RF switches, MEMs switches, PIN diodes and varactor diodes have been used in reconfigurable antenna designs. The varactor diodes in particular seem to offer a rich possibility for future designs over a wide frequency range, due to their excellent DC voltage-controlled reactance property.[7]

For the conventional PIFA antennas, each PIFA-patch element will be designed carefully based on approximately equation. This equation is a very rough approximation which does not cover all the parameters which significantly affect the resonance frequency of PIFA.

$$
F r=c /(4(L p+W p) \sqrt{\varepsilon r})
$$

Where:

fr is the resonance frequency at desired band.

Lp is the length of the radiating element.

$\mathrm{Wp}$ is the width of the radiating element.

$\varepsilon \mathrm{r}$ is the dielectric constant of the substrate.

$\mathrm{c}$ is the speed of light. 


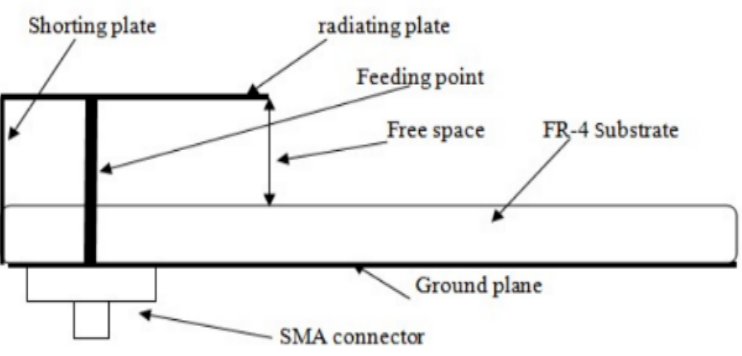

Figure 1. The geometry of the PIFA antenna proposed

The configuration of the PIFA is shown in Figure 1. The radiating plate has the dimensions of $\mathrm{Wp} \times \mathrm{Lp}$ (Figure 2.1) and ground plane dimensions are $\mathrm{Wg} \times \mathrm{Lg}$. There is an FR-4 substrate has a relative dielectric constant of 4.4 and it is between the rectangular ground plane and radiating plate. The antenna height is $\mathrm{h}=\mathrm{ha}+\mathrm{hs}$ and the space between the top plate and the substrate are also filled with air (free space). In practice, a substrate is generally just underneath the top plate, but this will make the top plate too heavy to be supported by the shorting and feeding plates. The shorting plate with the dimensions of $\mathrm{Wsh} \times \mathrm{h}$ is placed under the top corner of the top plate. The horizontal distance between shorting and feed plates is $\mathrm{x}$. The distance between the coaxial cable and the right edge of the ground plane is $\mathrm{Wp} / 2$ and even for shorting plate. The PIFA antenna is fed by a coaxial cable through a subminiature version A (SMA) connector.[8]

\section{PLANAR INVERTED F ANTENNA U- SHAPED}

Generally, PIFA consists of ground plane, patch, probe or shorting pin which is the connector between patch and ground plane. PIFA can be configured to work at several frequencies, like dualband, triband, and quadband with adding extra slot in its patch. The addition of the slot can affect antenna characteristic, like frequency resonant.

To find the antenna dimensions, length and width, it is necessary to know in advance the parameters of the material to be used, namely dielectric height, dielectric constant, conductor thickness, and material losses. The antenna patch can be calculated using the equation. [9]

$$
W+L=\lambda / 4
$$

Where:

$$
\begin{aligned}
& \text { - } \quad \mathrm{W} \text { is the width of antenna patch. } \\
& \text { - } \quad \mathrm{L} \text { is the length of antenna patch. } \\
& \quad \lambda \text { is the wave length. }
\end{aligned}
$$

The length and width of the slot on the PIFA with the U-shape are calculated in the same way as the L-shape, using equation (1). Example of U-Slot on PIFA is shown in Figure 2.[10]

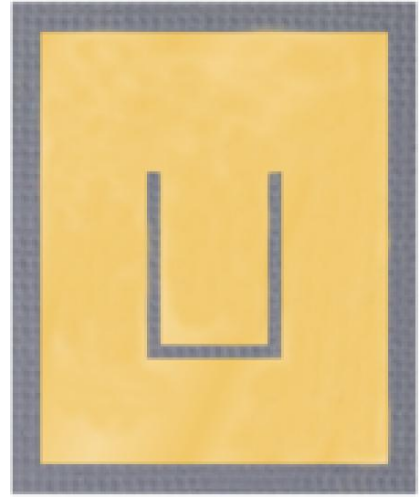

Figure 2 PIFA U-shaped

\section{DESIGN PROCESS OF U-SHAPED} PIFA

The antenna design process is carried out in the Antenna Magus software. Antenna Magus is a useful software to accelerate the process of designing and modeling an antenna. This software increases efficiency by helping engineers by providing and informing about the choice of antenna elements, for good design. This software is also integrated with the CST Studio Suite 2020 software; therefore, this makes the design process easier. [11]

From the software, the parameter obtained:

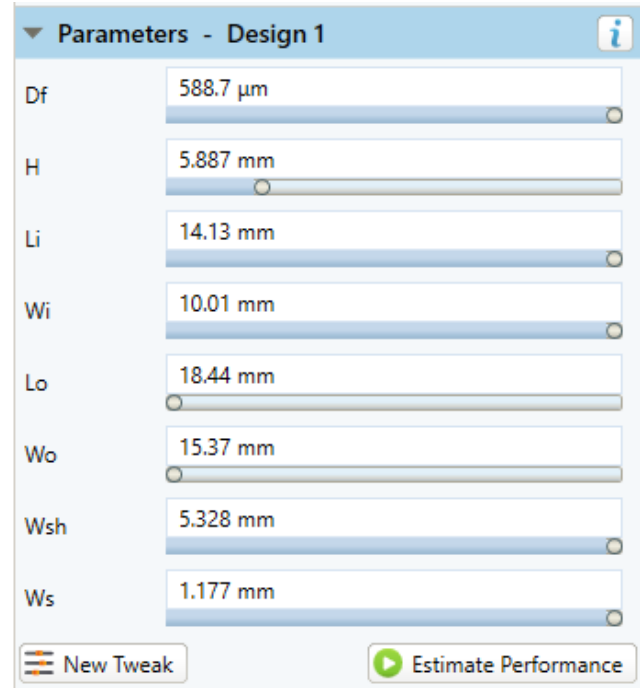

Figure 3 Dimension parameters PIFA U-shaped in Antenna Magus

The antenna has several dimensions of $\mathrm{X}, \mathrm{Y}, \mathrm{Z}$, such as: $X=15.37 \mathrm{~mm}$. $Y=18.44 \mathrm{~mm} . \mathrm{Z}=5.887 \mathrm{~mm}$. and $\mathrm{Ss}=1.568 \mathrm{~mm}$.

\section{SIMULATION PROCESS OF U- SHAPED PIFA}

The results of the PIFA U-shaped simulation will be shown. The simulation results are the temporary results of the antenna before the antenna goes through the optimization process and get ideal results such as VSWR $\leq 1$, reference impedance 50 $\Omega$, s-parameter below $-20 \mathrm{~dB}$, and working frequencies at 2.4 $\mathrm{GHz}$ and $3.7 \mathrm{GHz}$.

From the software, the parameter obtained: 


\begin{tabular}{|c|c|c|c|c|}
\hline \multicolumn{5}{|c|}{ Parameter List } \\
\hline$\nabla$ & Name & Expression & Value & Description \\
\hline$-\square$ & wavelength_centre & $=\mathrm{c} 0 /($ frequency_minimum $/ 2+$ frequency_maximum $/ 2$ ) & 94.2743578616352 & \\
\hline$-\square$ & slot_width & $=1.1774721193495$ & 1.1774721193495 & Slot width \\
\hline$\rightarrow$ & slot_offset & $=0$ & 0 & \\
\hline$\rightarrow$ & shorting_strip_width & $=5.3279281702696$ & 5.3279281702696 & Width of shorting plate \\
\hline$-\square$ & plate_outer_width & $=15.3690096525464$ & 15.3690096525464 & Outer element width \\
\hline$-\square$ & plate_outer_length & $=18.4428115830556$ & 18.4428115830556 & Outer element length \\
\hline$\rightarrow$ & plate_inner_width & $=10.0068452069363$ & 10.0068452069363 & Inner element width \\
\hline$\rightarrow$ & plate_inner_length & $=14.129665432194$ & 14.129665432194 & Inner element length \\
\hline$\rightarrow$ & plate_height & $=5.88736059674749$ & 5.88736059674749 & Plate height \\
\hline-4 & metal_thickness & = wavelength_centre/1000 & $9.42743578616352 \mathrm{e}-02$ & \\
\hline$\rightarrow$ & gnd_width & = plate_outer_width³ & 46.1070289576392 & \\
\hline$-\square$ & gnd_length & $=$ plate_outer_length*3 & 55.3284347491668 & \\
\hline$\rightarrow$ & frequency_minimum & $=$ frequency_centre_ $1 * 0.8$ & 1.92 & \\
\hline-4 & frequency_maximum & $=$ frequency_centre_2*1.2 & 4.44 & \\
\hline$-\square$ & frequency_centre_2 & $=3.7$ & 3.7 & Second operating frequency \\
\hline$\rightarrow$ & frequency_centre_1 & $=2.4$ & 2.4 & First operating frequency \\
\hline$-\square$ & feed_offset_y & $=0$ & 0 & \\
\hline$-\rightarrow$ & feed_offset_x & $=0$ & 0 & \\
\hline$\rightarrow$ & feed_diameter & $=0.58873605967475$ & 0.58873605967475 & Diameter of feed pin \\
\hline$\rightarrow$ & co & $=$ CLight*1E-06 & 299.792458 & Speed of light (corrected for the model units) \\
\hline$\rightarrow$ & coaxial_length & $=$ wavelength_centre/ 15 & 6.28495719077568 & \\
\hline-4 & coaxial_outer_diameter & $=$ feed_diameter $/ 0.4343$ & 1.35559765064414 & \\
\hline$\rightarrow$ & coaxial_relative_permittivity & $=1$ & 1 & \\
\hline$\rightarrow$ & coaxial_inner_diameter & = feed_diameter & 0.58873605967475 & \\
\hline
\end{tabular}

Figure 4 CST Studio Suite 2020 parameter value list before optimization

After the result obtained, and do some optimization, the result changed to:

\section{SIMULATION RESULT OF U- SHAPED PIFA}

Figure 5 is the simulation result in the CST Studio Suite 2020 software in the form of a PIFA U-shaped antenna displayed in 3D. The simulated antenna can be rotated and enlarged as desired.

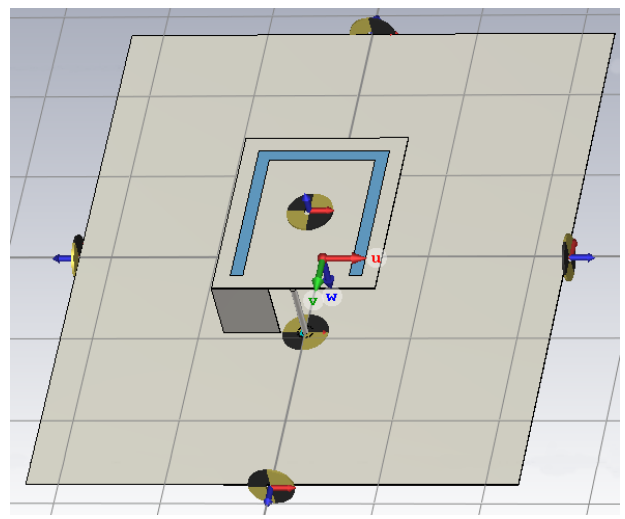

Figure 5 PIFA U-shaped before optimization

\section{U-SHAPED PIFA OPTIMIZATION RESULTS}

After examining changes in antenna dimension elements, optimization of the U-shaped PIFA is simulated in the CST Studio Suite 2020 software. The antenna optimization process will be carried out in the same software. Antenna optimization is done by implementing the research results obtained in Section 4.2. The intended implementation is by using the method of matching and combining antenna dimensional elements so that the antenna parameters are in accordance with the IEEE setting. The antenna parameter set according to IEEE is a VSWR value $\leq 1$, reference impedance $50 \Omega$, sparameter below $-20 \mathrm{~dB}$.

From the software, the parameter obtained: 


\begin{tabular}{|c|c|c|c|c|}
\hline \multicolumn{4}{|c|}{ Parameter List } & \multirow[t]{2}{*}{ 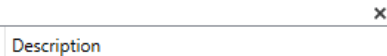 } \\
\hline$\nabla$ & Name & Expression & Value & \\
\hline-4 & wavelength_centre & $=\mathrm{c0} /($ frequency_minimum $/ 2+$ frequency_maximum $/ 2$ ) & 94.2743578616352 & \\
\hline$\rightarrow$ & slot_width & $=1.2$ & 1.2 & Slot width \\
\hline$\rightarrow$ & slot_offset & $=0$ & 0 & \\
\hline- & shorting_strip_width & $=5.5$ & 5.5 & Width of shorting plate \\
\hline$-\square$ & plate_outer_width & $=15.5$ & 15.5 & Outer element width \\
\hline$\rightarrow$ & plate_outer_length & $=18$ & 18 & Outer element length \\
\hline$-\square$ & plate_inner_width & $=10$ & 10 & Inner element width \\
\hline-4 & plate_inner_length & $=14$ & 14 & Inner element length \\
\hline$\rightarrow$ & plate_height & $=6$ & 6 & Plate height \\
\hline$\rightarrow$ & metal_thickness & $=$ wavelength_centre $/ 1000$ & $9.42743578616352 \mathrm{e}-02$ & \\
\hline$\rightarrow$ & gnd_width & $=$ plate_outer_width*3 & 46.5 & \\
\hline$-\square$ & gnd_length & = plate_outer_length*3 & 54 & \\
\hline$-\rightarrow$ & frequency_minimum & $=$ frequency_centre_ $1 * 0.8$ & 1.92 & \\
\hline$\rightarrow$ & frequency_maximum & $=$ frequency_centre_ $2 * 1.2$ & 4.44 & \\
\hline$\rightarrow$ & frequency_centre_2 & $=3.7$ & 3.7 & Second operating frequency \\
\hline$\rightarrow$ & frequency_centre_1 & $=2.4$ & 2.4 & First operating frequency \\
\hline$\rightarrow$ & feed_offset_y & $=0$ & 0 & \\
\hline$\rightarrow$ & feed_offset_x & $=0$ & 0 & \\
\hline$\rightarrow$ & feed_diameter & $=0.58873605967475$ & 0.58873605967475 & Diameter of feed pin \\
\hline$\rightarrow$ & co & $=$ CLight ${ }^{\star} 1 \mathrm{E}-06$ & 299.792458 & Speed of light (corrected for the model units) \\
\hline$\rightarrow$ & coaxial_length & $=$ wavelength_centre $/ 15$ & 6.28495719077568 & \\
\hline$-\square$ & coaxial_outer_diameter & $=$ feed_diameter $/ 0.4343$ & 1.35559765064414 & \\
\hline$\rightarrow$ & coaxial_relative_permittivity & $=1$ & 1 & \\
\hline$\rightarrow$ & coaxial_inner_diameter & = feed_diameter & 0.58873605967475 & \\
\hline
\end{tabular}

Figure 6 CST Studio Suite 2020 parameter value list after optimization

\subsection{PIFA U-SHAPED RETURN LOSS VALUE AFTER OPTIMIZATION}

Figure 7 and Figure 8 are the results of the S-parameter or PIFA U-shaped Return loss after going through the optimization process. The optimization process carried out in the process is to conduct research by changing the antenna The first PIFA U-shaped slot has a value of -26.369808 at $2.4215 \mathrm{GHz}$.

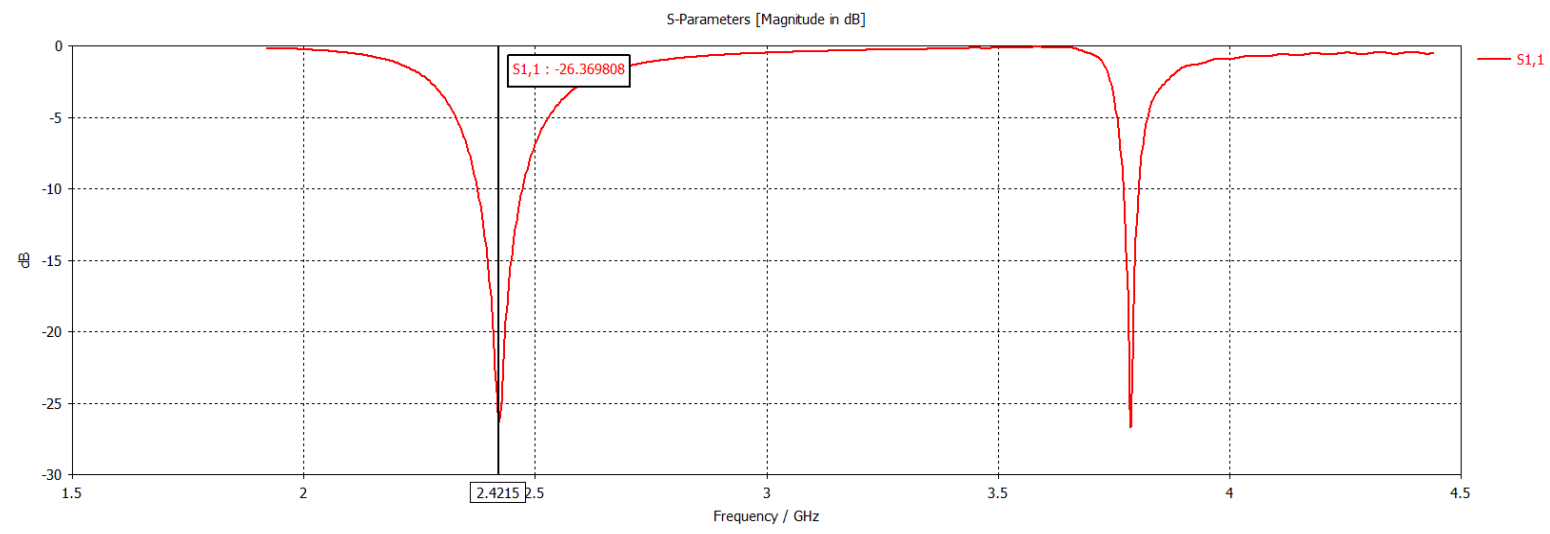

Figure 7 Return Loss slot 1 PIFA U-shaped after optimization dimension element coefficient. Figure 14 will display the return loss value in the first slot of the antenna, while Figure 15 will display the return loss value in the second slot of the antenna.

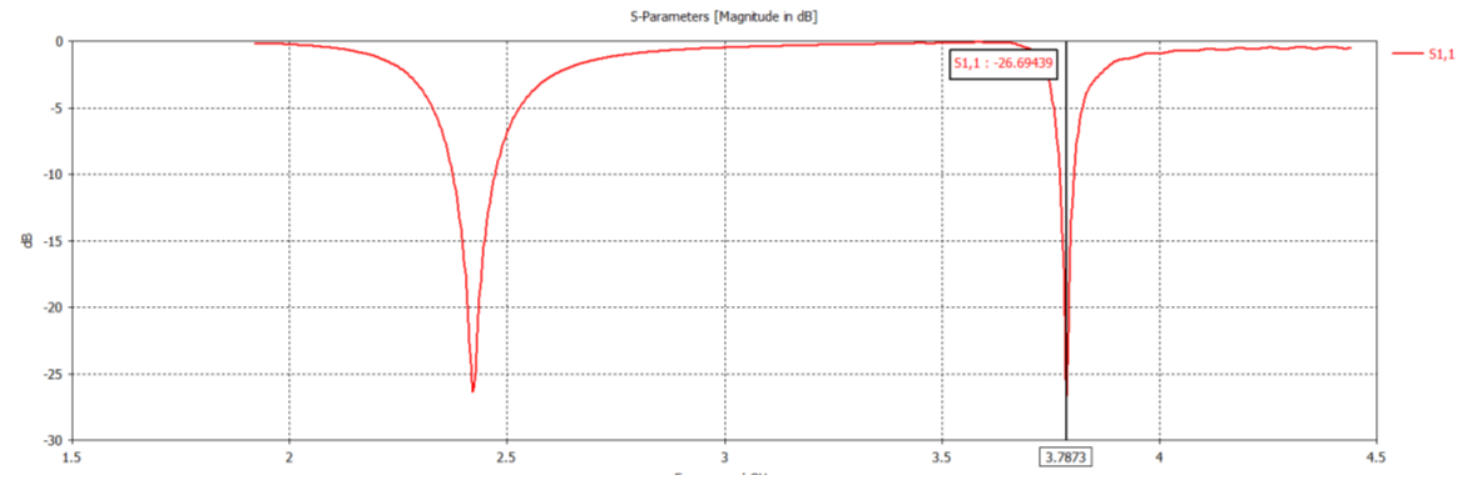

Figure 8 Return Loss slot 2 PIFA U-shaped after optimization 


\subsection{U-shaped PIFA VSWR Value After Optimization}

To find the VSWR value, a formula is used as regarding the VSWR PIFA U-shaped value before optimization, where

$V S W R=\frac{1+10 \frac{-R L}{20}}{1-10 \frac{-R L}{20}}$

Where RL is Return Loss, so we get VSWR for PIFA before optimization which is symbolized by VSWR1 for VSWR value in the first slot, and VSWR2 in the second slot.

\subsection{PIFA U-shaped Line Impedance Value After Optimization}

Figure 14 is the Line Impedance PIFA U-shaped value which implementation will be connected to the coaxial transmission media. Coaxial is used because it has a commonly used impedance of $50 \Omega$. In this study, the value obtained was 50.150508 where the antenna has a tolerance of 0.150508 .

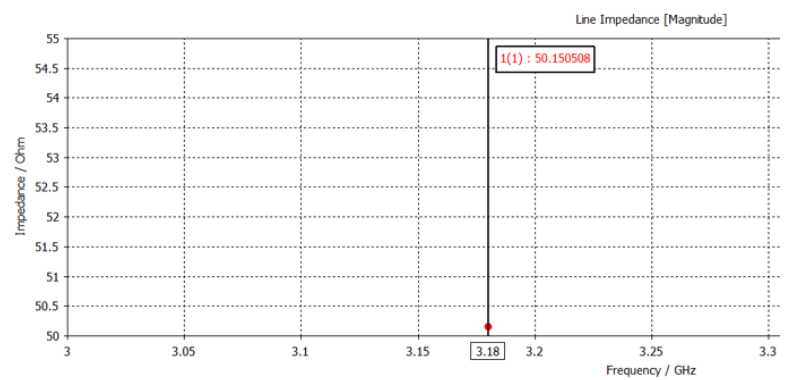

Figure 9 PIFA U-shaped Line Impedance after optimization

\subsection{U-shaped PIFA Gain Value After Optimization}

As explained above, the U-shaped PIFA emission pattern is omnidirectional. In Figure 15 and Figure 16, the antenna gain results are shown in the form of a 2D image with the value in the form of the main lobe magnitude, which is $3.49 \mathrm{dBi}$ at a frequency of $2.4 \mathrm{GHz}$. This result is the gain in slot 1 PIFA Ushaped.

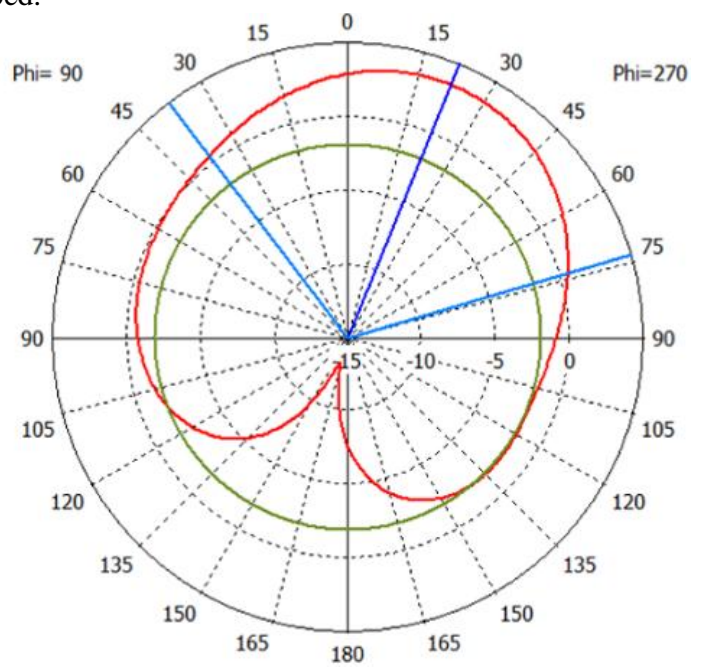

Figure 10 PIFA U-shaped gain after optimization at 2.4 GHz

Whereas in Figure 18 it is explained that the research results are in the form of a gain in slot 2 PIFA U-shaped which gets a value of $2.82 \mathrm{dBi}$ at a frequency of $3.7 \mathrm{GHz}$.

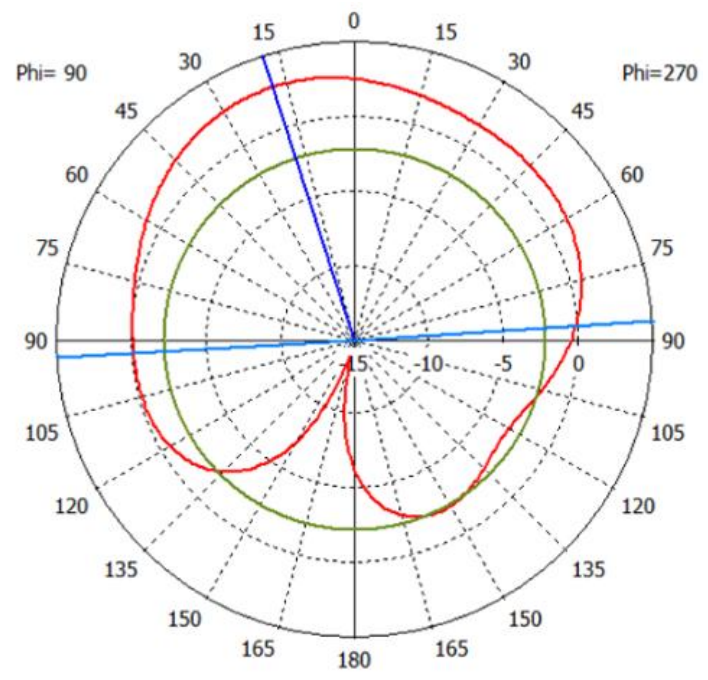

Figure 11 PIFA U-shaped gain after optimization at 3.7 GHz

\section{COMPARISON OF PIFA U-SHAPED BEFORE AND AFTER OPTIMIZATION}

The process of comparing the PIFA U-shaped results is done by comparing the antenna parameters before and after the optimization process. The comparison results will be displayed in two tables, namely table 1 and table 2 . Comparisons were made with two tables to simplify the reading process. Table 1 will present the parameter results in slot 1 PIFA U-shaped, while for slot 2 PIFA U-shaped will be presented in table 2 .

Table 1 The Comparison Result of Slot 1

\begin{tabular}{|c|c|c|c|c|}
\hline & Parameters & Before & After & $\begin{array}{c}\text { Error } \\
\text { Percentage }\end{array}$ \\
\hline $\mathbf{1}$ & Return Loss & $\mathbf{- 1 6 . 5 8 1 7 4 5}$ & $\mathbf{- 2 6 . 3 6 9 8 0 8}$ & $59.02 \%$ \\
\hline & at freq $(\mathrm{GHz})$ & 2.4164 & 2.4215 & \\
\hline $\mathbf{2}$ & VSWR & $\mathbf{1 . 3 4 8 0 2 9 7 3}$ & $\mathbf{1 . 1 0 0 9 0 5 8 1}$ & $18.33 \%$ \\
\hline & at freq $(\mathrm{GHz})$ & 2.4164 & 2.4215 & \\
\hline $\mathbf{3}$ & Line Impedance $\mathbf{(} \mathbf{\Omega})$ & $\mathbf{5 0 . 1 5 0 5 0 8}$ & $\mathbf{5 0 . 1 5 0 5 0 8}$ & 0 \\
\hline & Tolerance $(\boldsymbol{\Omega})$ & 0.150508 & 0.150508 & \\
\hline $\mathbf{4}$ & Gain $\mathbf{( d B i}$ & 3.5 & 3.49 & $0.3 \%$ \\
\hline
\end{tabular}

Table 2 The Comparison Result of Slot 2

\begin{tabular}{|c|c|c|c|c|}
\hline & Parameters & Before & After & $\begin{array}{c}\text { Error } \\
\text { Percentage }\end{array}$ \\
\hline $\mathbf{1}$ & Return Loss & $\mathbf{- 1 7 . 6 8 1 9 5}$ & $\mathbf{- 2 6 . 6 9 4 3 9}$ & $50.97 \%$ \\
\hline & at frea $(\mathrm{GHz})$ & 3.7848 & 3.7873 & \\
\hline $\mathbf{2}$ & VSWR & $\mathbf{1 . 3 0 0 4 0 4 7 2}$ & $\mathbf{1 . 0 9 7 0 2 5 1 1}$ & $15.64 \%$ \\
\hline & at frea $(\mathrm{GHz})$ & 3.7848 & 3.7873 & \\
\hline $\mathbf{3}$ & Line Impedance $\mathbf{(} \mathbf{)}$ & $\mathbf{5 0 . 1 5 0 5 0 8}$ & $\mathbf{5 0 . 1 5 0 5 0 3}$ & 0 \\
\hline & Tolerance $(\boldsymbol{\Omega})$ & 0.150508 & 0.150508 & \\
\hline $\mathbf{4}$ & Gain $\mathbf{( d B i}$ & 2.32 & 2.82 & $17.73 \%$ \\
\hline
\end{tabular}

Error percentage is the comparation percentage between before and after. Error percentage can be calculated by equation:

Error percentage $=(\mid$ before - after $\mid) \mid$ (|before $\mid$ ) X 100\%

For the gain of slot 2 can be calculated by:

Error percentage $=(\mid$ after - before $\mid) /$ (|after $\mid) \times 100 \%(6)$

Because the after value is bigger than Simulation. 


\section{CONCLUSIONS}

Based on the previous four chapters, objectives, research methods, analysis, and research results, several points can be concluded, such as:

1. The research is focused on the design and simulation of a U-shaped PIFA antenna for 5G communication at $2.4 \mathrm{GHz}$ and $3.7 \mathrm{GHz}$ working frequencies.

2. There are several important aspects in the design, namely the dimensional elements of the antenna. This research discusses the effect of changes in antenna dimensional elements on changes in the results of antenna parameters. The antenna dimensions discussed include the diameter of feed pin, plate height, inner element length, inner element width, outer element length, outer element width, width of shorting plate, and slot width.

3. The research results are shown by describing the simulation results of the PIFA U-shaped after optimization to obtain antenna parameters. The results obtained are VSWR which is divided into slot 1 which gets a value of 1.10090581 and slot 2 which has a value of 1.09702511. The return loss value obtained in slot 1 is -26.369808 , and slot 2 is 26.69439. The gain obtained in slot 1 is $3.49 \mathrm{dBi}$ and in slot 2 is $2.82 \mathrm{dBi}$. PIFA U-shaped can work with coaxial transmission media with an antenna line impedance of $50.150508 \Omega$.

\section{ACKNOWLEDGMENTS}

The author would like to thank Gunadarma University, my family, and all those who have support in completing this paper, both morally and materially. Especially my advisor, $\mathrm{Mr}$ Debyo Saptono, who has provided guidance and advice to the author so that this final project can be completed properly.

\section{REFERENCES}

[1] Mustapha El Halaoui, Hassan Asselman., "Design and simulation of a planar inverted-F antenna (PIFA) for WiFi and LTE Applications", Optics and Photonics group, Faculty of Science, Abdelmalek Essaadi University, Tétouan, Morocco. 2014.

[2] Mondir Anouar, Pr.Setti Larbi., "PIFA Antenna for future mobile 5G", advanced science and technology laboratories Department of physic UAE MORROCO. 2018.

[3] Sainz, Manuel., "5G Techniques", Department of Electronic Systems, Aalborg University. 2015.

[4] Ying Zhinong., "Antennas in Cellular Phones for Mobile Communications", Department of Electronic Engineering Zhejiang Normal University, China. 2012.

[5] N. Belgacem, M abri., "A Compact Multi-band PIFA Antenna for UMTS and WLAN Mobile Applications", Telecommunication Laboratory, Faculty of Technology, University of Tlemcen, Algeria. 2017.

[6] Andrews, Jeffrey G; Buzzi, Stefano; Hanly, Stephen V; Soong, Anthony., "What will 5G be?", IEEE Journal on Selected Areas in Communications, USA. 2014.

[7] Umair Rafique, Hisham Khalil., "Dual-band Microstrip Patch Antenna Array for 5G Mobile Communications", Department of Electrical Engineering, Capital University of Science and Technology, Islamabad, Pakistan. 2017.

[8] Mohamad khlouf Munzer, Saidatul Norlyana Azemi., "Dual Band Planar Inverted F Antenna (PIFA) with LShape Configuration", Advanced Communication Engineering Centre (ACE) CoE, School of Computer and Communication Engineering, Universiti Malaysia Perlis (UniMAP), Pauh Putra, Arau 02600, Malaysia. 2017.

[9] Yuming Nie, Lizhong Song., "A Compact Triband Fractal PIFA Antenna for Mobile Handset Applications", Department of Electronics and Information Engineering Harbin Institute of Technology Harbin, China. 2013.

[10] Elias, Bashar Bahaa Noori Qas., "Analysis of Different Structures of Patch Antennas", Master of Science in Electrical and Electronic Engineering Eastern Mediterranean University, Gazimagusa, North Cyprus. 2014.

[11] Udit Raithatha, S. Sreenath Kashyap., "Microstrip Patch Antenna Parameters, Feeding Techniques \& Shapes of the Patch - A Survey", Department of Electronics and Communications Engineering Marwadi Education Foundation's Group of Institutions. 2015. 